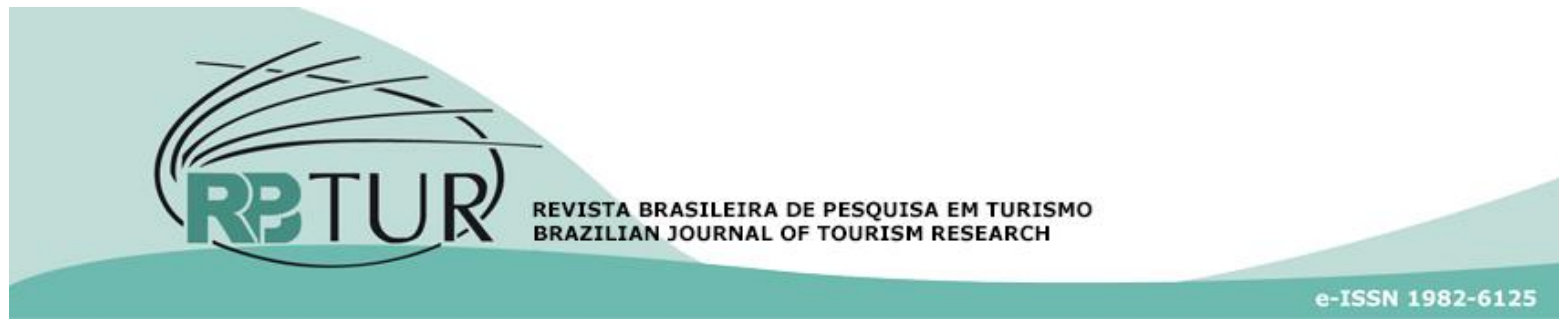

\title{
Artigos
}

\section{Análise bibliométrica da produção científica sobre turismo de base comunitária de 2013 a 2018}

\author{
Bibliometric analysis of the scientific literature on community-based \\ tourism from 2013 to 2018
}

\section{Análisis bibliométrico de la producción científica sobre turismo de base comunitario de 2013 a 2018.}

\author{
Pollyanna Fraga Graciano ${ }^{1}$, Luciana Araújo de Holanda ${ }^{1}$ \\ 1Universidade Federal de Pernambuco (UFPE), Recife, PE, Brasil.
}

Palavras-chave:

Turismo de Base Comunitária. Revisão Integrativa da Literatura. Bibliometria.

Keywords:

Community-Based Tourism. Literature's Integrative Review. Bibliometry

\section{Palabras clave:}

Turismo de Base Comunitaria. Revisión Integrativa de la Literatura. Bibliometría

\section{Resumo}

O Turismo de Base Comunitária é uma proposta para o planejamento e o desenvolvimento das localidades através da atividade turística, fundamentada nos conceitos de sustentabilidade e desenvolvimento sustentável, promovendo a emancipação social das comunidades por meio do protagonismo da população na autogestão de seus bens, serviços e capital social, para assim atingir a melhoria da qualidade de vida de seus moradores e a conservação de seu patrimônio ambiental, histórico e cultural. Com o objetivo de compreender a produção científica, que ganhou espaço a partir de 1990, e identificar possíveis lacunas sobre tema, este artigo reúne Revisão Integrativa da Literatura (RIL) ao Estudo Bibliométrico (EB) para analisar uma amostra de 158 artigos em português, espanhol e inglês distribuídos por 64 periódicos. 0 estudo cumpriu as três principais leis da bibliometria: Lotka, Bradford e Zipf, indicando o TBC como uma temática em expansão e com produção pulverizada. Por fim, a síntese dos conhecimentos produzidos identificou como possíveis lacunas teóricas: governança e comercialização.

\section{Abstract}

Community-Based Tourism is a proposal for planning and developing localities through tourism, based on the sustainability and sustainable development's concepts, promoting the communities' social emancipation through the population's leading role in self-management of their goods, services and social capital, in order to achieve the improvement of the quality of life of its residents and the conservation of its environmental, historical and cultural heritage. In order to understand the scientific literature that has gained space since 1990, and to identify possible gaps in the subject, this article brings together an Literature's Integrative Review (LIR) and a Bibliometric Study (BS) to analyze a sample of 158 articles in Portuguese, Spanish and English distributed by 64 journals. The study fulfilled the three main bibliometric's laws: Lotka, Bradford and Zipf, indicating the CBT as an expanding and pulverized production theme. Finally, the synthesis of knowledge identified as possible theoretical gaps: governance and commercialization.

\section{Resumen}

El Turismo de Base Comunitaria es una propuesta para la planificación y el desarrollo de las localidades a través de la actividad turística, fundamentada en los conceptos de sustentabilidad y desarrollo sostenible, promoviendo la emancipación social de las comunidades a través del protagonismo de la población en la autogestión de sus bienes, servicios y capital 
Revisado por pares. Recebido em: 24/05/2019. Aprovado em: 27/07/2019. social, para así alcanzar la mejora de la calidad de vida de sus habitantes y la conservación de su patrimonio ambiental, histórico y cultural. Con el fin de entender la producción científica, que ha ganado terreno desde 1990, e identificar posibles deficiencias en el tema, este artículo reúne la Revisión Integrativa de la Literatura (RIL) com el Estudio bibliométrico (EB) para analizar una muestra de 158 artículos en portugués, español e inglés distribuidos por 64 periódicos. El estudio cumplió las tres principales leyes de la bibliometría: Lotka, Bradford y Zipf, indicando el TBC como una temática en expansión y con producción pulverizada. Por último, la síntesis de los conocimientos producidos identificó como posibles lagunas teóricas: gobernanza y comercialización.

Como citar: Graciano, P. F. ; Holanda, L. A. (2020). Análise bibliométrica da produção científica sobre turismo de base comunitária de 2013 a 2018. Revista Brasileira de Pesquisa em Turismo, São Paulo, 14 (1), p. 161-179, jan./abr. http://dx.doi.org/10.7784/rbtur.v14i1.1736

\section{INTRODUÇÃO}

O Turismo de Base Comunitária (TBC) atingiu os debates acadêmicos desde a década de 1990 no Brasil por integrar-se ao movimento do turismo alternativo como um contraponto à massificação do fenômeno turístico. Essa nova corrente emerge da necessidade de atender a uma demanda de turistas responsáveis preocupados com as consequências de suas viagens para os lugares visitados. Reunido ao discurso da sustentabilidade, fortalecida neste período, o TBC evidencia-se por promover o desenvolvimento local sustentável das comunidades e a emancipação social através da atividade turística, melhorando a qualidade de vida e gerando divisas para a população local (Burgos \& Mertens, 2015; Irving \& Azevedo, 2002; Maldonado, 2009; Okazaki, 2008).

O TBC almeja proporcionar às comunidades uma segunda fonte de renda, melhoria da qualidade de vida e protagonismo. Algumas iniciativas sofrem influência de agentes exógenos como ONGs e instituições de ensino superior, que acompanham as comunidades na elaboração e implantação do TBC. Após a saída destas instituições, poucas sobrevivem, culminando na alta mortalidade das iniciativas (Mielke, 2009). As comunidades apresentam muitos problemas: o despreparo da população, a ausência de profissionalismo, inexistência de ferramentas de gestão, falta de informação e falha na comunicação (Hallack, Burgos, \& Carneiro, 2011; Maldonado, 2009).

Ao integrar o fenômeno turístico, o TBC evidencia uma multiplicidade de conceitos e definições, concebendo dificuldades epistemológicas prejudiciais à evolução do tema. Apesar dos esforços acadêmicos para classificar, orientar e normatizar uma epistemologia própria, a vastidão temática dificulta esta delimitação. As abordagens são superficiais e impossibilitam um aprofundamento das questões reais. 0 aprisionamento de muitos pesquisadores a velhos padrões positivistas se traduz em artigos descritivos e estatísticos, pouco refletindo o contexto humano e social. A cientificidade dos debates resultará da capacidade crítica e reflexiva sobre as novas tendências da investigação (Nechar \& Panosso Netto, 2010), que alcançará uma epistemologia mais crítica através de esforços coletivos.

Conscientes desses impasses, este estudo objetiva compreender a produção cientifica e identificar possíveis lacunas sobre o tema. Assim, optou-se por integrar a Revisão Integrativa da Literatura (RIL) ao Estudo Bibliométrico (EB) para conhecer e aprofundar o pensamento produzido sobre o TBC. 0 artigo está divido em três seções, além da introdução. A segunda seção aborda os procedimentos metodológicos, seguida da seção que agrega as fases da RIL, e por fim, as conclusões.

\section{PROCEDIMENTOS METODOLÓGICOS}

A RIL é uma técnica metodológica que inclui produções teóricas e empíricas utilizando abordagens quantitativas e qualitativas. Essa multiplicidade permitirá um profuso panorama de conceitos, teorias ou dificuldades sobre a temática. A RIL possui seis fases: (i) identificação do tema; (ii) amostragem; (iii) categorização dos estudos; (iv) avaliação dos estudos incluídos; (v) interpretação dos resultados; e (vi) síntese do conhecimento encontrado (Torraco, 2016). 
$\mathrm{Na}$ primeira etapa, foram descritas as origens e conceitos do TBC. Na etapa de amostragem, realizou-se um EB da produção científica. A bibliometria consiste na utilização de técnicas quantitativas e estatísticas para medir a produção e a transmissão do conhecimento científico, além de relatar padrões da comunicação escrita e aspectos da literatura (Koseoglu, Rahimi, Okumus, \& Liu, 2016). Hall (2011) relaciona três razões para este tipo de análise: (i) crescimento dos estudos sobre turismo; (ii) contribuição de indivíduos, publicações e instituições para a literatura turística; e (iii) avaliação do desempenho dos estudos. O EB permite delinear o comportamento e o desenvolvimento da área de conhecimento. A Figura 1 demonstra como ocorreu a fusão entre RIL e EB.

Figura 1 - Desenho da pesquisa

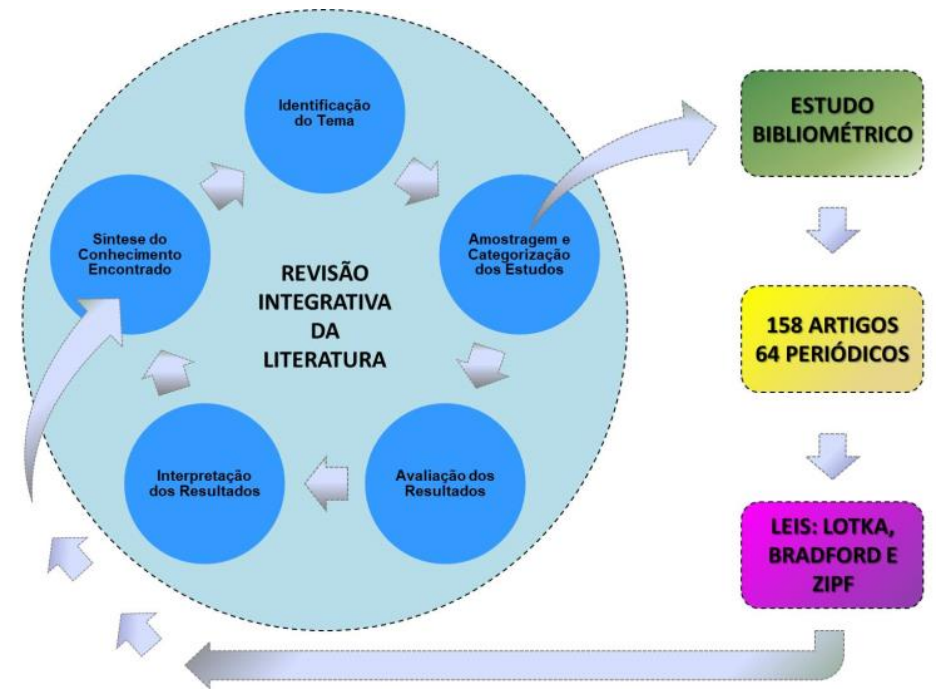

Fonte: Elaborado pelas autoras (2018)

A amostra das produções ocorreu inicialmente pelo Portal Periódicos Capes, por disponibilizar um acervo de 53 mil títulos provenientes de 129 bases. 0 recorte temporal delimitado foi de janeiro de 2013 a outubro de 2018 para continuar à revisão de literatura realizada por Albuquerque (2016) e Fabrino (2013). Selecionaram-se artigos que apresentaram os termos "turismo de base comunitária" ou "turismo comunitário", em português e inglês, no título, encontrando um total de 103 artigos em língua inglesa, espanhola e portuguesa. Após avaliação, foram excluídos 12 artigos duplicados, restando 91 artigos.

A análise preliminar das produções identificou que não apareceram nos resultados das buscas alguns dos proeminentes periódicos brasileiros especializados em turismo. Assim, realizou-se a mesma busca na plataforma Publicações de Turismo, mantida pelo Programa de Pós-graduação em Turismo (PPGTUR) da USP. Identificaram-se 118 publicações sobre o tema, e excluindo os artigos duplicados, obteve-se um universo de 67 artigos, distribuídos por 14 periódicos, conforme demonstra o Quadro 1.

A base do EB proposto será uma amostra de 158 produções distribuídas por 64 periódicos, na qual foram aplicadas as Leis: de Lotka, de Bradford e de Zipf. A Lei de Lotka demonstra a existência de uma "relação quantitativa entre a frequência de autores produzindo um número x de trabalhos" (Quevedo-Silva, Santos, Brandão, \& Vils, 2016:248), ou seja, uma pequena quantidade de autores possui uma grande produção de literatura científica, e um grande número de autores se iguala em produção ao pequeno número de autores (Thompson \& Walker, 2015). A análise permite reconhecer os expoentes da pesquisa sobre o assunto.

A Lei de Bradford trata da dispersão de artigos pelos periódicos, comprovando que um número menor de periódicos possuem muitas produções sobre o tema, enquanto um número maior possuirá poucos artigos. Os periódicos dividem-se em núcleo e zonas produtivas, nas quais a razão do número de revistas em qualquer zona pelo número de revistas na zona precedente é chamada de "multiplicador de Bradford" ( $\left.B_{m}\right)(Q u e-$ vedo-Silva et al., 2016; Thompson \& Walker, 2015). Esta lei identificará os periódicos mais relevantes sobre a temática, auxiliando na revisão de literatura e na escolha de revistas para publicação de artigos. 
Quadro 1 - Periódicos brasileiros e produção sobre TBC

\begin{tabular}{|c|c|c|c|c|}
\hline$N^{\circ}$. & ISSN & Título & $\begin{array}{c}\text { Classificação Qua- } \\
\text { lis-CAPES 2013- } \\
2016\end{array}$ & $\begin{array}{l}\text { Quantidade } \\
\text { de Artigos }\end{array}$ \\
\hline 1 & $1982-6125$ & Revista Brasileira de Pesquisa em Turismo & A2 & 3 \\
\hline 2 & $1677-6976$ & Caderno Virtual de Turismo & B1 & 23 \\
\hline 3 & $1983-7151$ & Turismo: Visão e Ação & B1 & 3 \\
\hline 4 & $1984-4867$ & Revista Turismo em Análise & B1 & 4 \\
\hline 5 & $2178-9061$ & Rosa dos Ventos - Turismo e Hospitalidade & B2 & 1 \\
\hline 6 & $1980-6965$ & $\begin{array}{c}\text { Revista Acadêmica Observatório de Inovação no Tu- } \\
\text { rismo }\end{array}$ & B2 & 1 \\
\hline 7 & $2236-6040$ & Revista Iberoamericana de Turismo & B3 & 3 \\
\hline 8 & $1983-9391$ & Revista Brasileira de Ecoturismo & B3 & 20 \\
\hline 9 & $1807-975 X$ & Revista Hospitalidade & B3 & 1 \\
\hline 10 & $1983-5442$ & Turismo e Sociedade & B4 & 2 \\
\hline 11 & $2316-1493$ & Revista Turismo Estudos e Práticas & B4 & 1 \\
\hline 12 & $2318-8561$ & Revista Cenário & B4 & 1 \\
\hline 13 & 2448-198X & Revista Latino Americana de Turismologia & B4 & 1 \\
\hline 14 & $1982-5838$ & Revista de Cultura e Turismo & B5 & 3 \\
\hline
\end{tabular}

Fonte: Elaborado pelas autoras (2018)

A Lei de Zipf demonstra que num conjunto de texto existirão palavras com alta frequência de ocorrência, aparecendo mais vezes que outras, assim, haverá uma pequena quantidade de palavras com muitas repetições e uma grande quantidade de palavras com poucas repetições (Quevedo-Silva et al., 2016). Comumente utilizada na linguística, esta lei permite mapear e criar um ranking de frequência de palavras, detectando palavras e/ou termos unânimes num campo de estudo. As mais frequentes são de alta e média relevância e as menos frequentes são consideradas ruídos.

A generalização da Teoria Epidêmica para a transmissão de ideias, desenvolvida por Goffman e Newill em 1964, defende que a disseminação do conhecimento ocorre de maneira similar à transmissão de doenças infecciosas (Araújo, 2006), e compreende a dinâmica da literatura. Analisaram-se os autores mais citados para evidenciar elos entre os indivíduos e suas áreas de pesquisa.

Na categorização dos estudos, elaborou-se uma planilha com a descrição, os conceitos chaves, os objetivos, os procedimentos metodológicos, os resultados e as conclusões. As duas últimas etapas realizaram a interpretação dos resultados e uma síntese dos achados teóricos presentes nos estudos representativos identificados pela bibliometria.

\section{REVISÃO DE LITERATURA}

\subsection{A evolução do turismo de base comunitária (TBC)}

O TBC iniciou em iniciativas da América Latina na década de 1980 através do Turismo Rural Comunitário (TCR), com incentivos do Banco Internacional de Desenvolvimento (BID), para suprir uma demanda internacional de turistas que buscavam contribuir para a preservação do meio ambiente e da diversidade das comunidades (Maldonado, 2009; Silva \& Martins, 2012). As iniciativas são mais frequentes no hemisfério sul, em continentes como África, Ásia, Oceania, como em países da América Latina, a saber: Brasil, Equador, México e Peru (López-Guzmán, Sánchez-Cañizares, \& Pavón, 2011). O desenvolvimento da atividade turística nas comunidades ocorre de muitas maneiras, pois cada região possui suas peculiaridades, que influenciam o processo. Contudo, esse excesso de variedade e a complexidade das comunidades dificultam a definição do TBC.

Segundo Sansolo e Bursztyn (2009), o TBC é uma proposta alternativa de gestão turística - endógeno e autônomo - buscando a diversificação econômica de sistemas produtivos locais, administrado pelas próprias comunidades. Maldonado (2009) o entende como a autogestão sustentável de recursos comunitários, enfatizando práticas de colaboração e equidade no trabalho e na distribuição de seus resultados, destacando a dimensão humana e cultural, pois incentiva os diálogos na comunidade e encontros interculturais. 
Coriolano (2009) define como arranjos produtivos locais, na qual associações comunitárias possuem o manejo das terras e das atividades econômicas relacionadas ao turismo. O MTUR (2010) aponta uma heterogeneidade de iniciativas de TBC em território brasileiro, por isso, não há uma definição profusamente aceita para esta nova prática. Assim, o Ministério define critérios para auxiliar em sua classificação: (i) a autogestão; (ii) o associativismo e cooperativismo; (iii) a democratização de oportunidades e benefícios; (iv) a centralidade da colaboração, parceria e participação; (v) a valorização da cultura local; e principalmente, (vi) o protagonismo das comunidades locais na gestão da atividade e/ou na oferta de bens e serviços turísticos.

Os conceitos de Turismo Comunitário (TC) e o Turismo de Base Comunitária (TBC) possuem distinções mesmo sendo tratados como sinônimos. Algumas definições de TC se voltam para a relação mercantil, ainda que embasados na equidade e na distribuição da renda. O TC é um segmento desenvolvido na comunidade e embora deseje produzir benefícios para esta, aproxima-se do turismo convencional: (i) comercializado por agências e operadoras não especializadas; (ii) população não é protagonista na gestão do turismo; e (iii) a renda gerada não é distribuída pela comunidade. Por outro lado, o TBC se apresenta como uma proposta de desenvolvimento local sustentável valorizando os costumes e as crenças da população, assumindo a posição de modelo de atividade turística no qual a comunidade é protagonista (Alves, 2013; Silva, Malta, \& Sá, 2016). Outros estudos distinguem o TBC das Empresas de Base Comunitária (EBC), definidas como organizações que exercem o empreendimento social coletivamente (Aldecua, 2011).

Fabrino, Nogueira e Pereira (2012) concluem que embora as iniciativas se estruturem de maneiras diferentes pelas complexidades locais, estes conceitos possuem perspectivas teóricas símiles quanto às dimensões antropológicas, sociológicas, econômicas, políticas, históricas, psicológicas e ambientais, sendo a comunidade um sujeito ativo do seu progresso, da concepção até a operação da atividade turística. Há a consciência que o êxito do desenvolvimento depende da cooperação social da população (Sen, 2010). Desta forma, embora a quantidade ainda seja um aspecto dominante, há uma corrente de pensamento que busca valorizar a qualidade nas relações turísticas (Zaoual, 2009).

O TBC centra-se na participação das comunidades por três razões: elas são parte do produto turístico, elas são facilmente adaptáveis às mudanças e elas devem ampliar os horizontes. Essa participação potencializa o estreitamento dos laços entre a comunidade e seus visitantes (López-Guzmán et al., 2011). 0 TBC incorpora características do turismo sustentável, apoiado em princípios e valores éticos. Embora defenda uma nova maneira de fazer turismo, esse fato não o torna sustentável, a sustentabilidade não é uma característica inerente, mas um objetivo a ser alcançado. O TBC tem nas atividades tradicionais o seu principal atrativo, alicerçando o seu desenvolvimento (Fabrino, Costa, \& Nascimento, 2012b).

Outro aspecto é a convivencialidade que consiste numa relação social interessada no outro, pela autenticidade nas tradições simples e nas rotinas. Caracterizada pela troca de experiências entre turistas e anfitriões, na qual os turistas vivenciam atividades rotineiras, superando o aspecto meramente mercantil das relações turísticas (Sampaio \& Coriolano, 2009; Sampaio \& Zamignan, 2012; Sampaio, Zechner, Henríquez, Coriolano, \& Fernandes, 2014).

Os benefícios econômicos não são a única potencialidade do TBC, pois ele colabora na continuidade do modo de vida das populações tradicionais ao contribuir para a valorização da identidade cultural das comunidades. O TBC emerge como a possibilidade de um novo paradigma do turismo, e não apenas como mais um segmento no mercado, devido à conservação ambiental, o reconhecimento da identidade cultural e os benefícios gerados para as populações receptoras (Sansolo \& Bursztyn, 2009). Para Burgos e Mertens (2015), apesar de ser um aliado na luta contra a pobreza, não pode associar-se apenas à geração de emprego e renda, mas deve atender uma expectativa mais ampla de bem-estar social e de qualidade ambiental das comunidades.

Desta forma, o TBC compreende a atividade turística como um fenômeno sistêmico integrado a outros subsistemas, tais como educação, saúde e meio ambiente, sendo este elemento que o diferencia dos demais. Logo, o TBC se configura numa proposta de desenvolvimento territorial sustentável abrangendo enfoque político, econômico, cultural e humano da sociedade (Sampaio \& Coriolano, 2009). 
As novas exigências da demanda turística mundial também incentivaram o mercado à inserção de novos atrativos em sua oferta habitual. Logo, a procura de fontes alternativas de renda e o desejo de superar a pobreza serviram de catalisador para atividades como as pequenas agroindústrias domésticas, o turismo e os ecos negócios em muitas comunidades. Destarte, este processo aumentará a sua dependência do mercado, desmembramento de territórios, perda da identidade cultural, enfraquecimento de suas instituições e da coesão social (Maldonado, 2009).

Na década de 1990, o I Encontro Nacional de Turismo de Base Local inseriu no meio acadêmico os estudos sobre TBC (Irving, 2009). Estes estudos foram impulsionados nacionalmente pela criação do grupo de pesquisa "Turismo e Desenvolvimento Social”, sediado no Laboratório de Tecnologia e Desenvolvimento Social (LTDS) da Universidade Federal do Rio de Janeiro (UFRJ), entre suas ações este grupo fundou o Instituto Virtual de Turismo (IVT) com o objetivo de manter uma rede ativa de pesquisadores e a publicação do Caderno Virtual de Turismo. No II Seminário Internacional de Turismo Sustentável realizado na cidade de Fortaleza - CE foi lançado o Edital $n^{\circ} 01 / 2008$ do MTUR para financiamento de projetos de turismo de base comunitária, destacando-se como primeira iniciativa do poder público federal para apoiar um modelo de turismo no qual as comunidades são protagonistas do processo (Bartholo, Sansolo, \& Bursztyn, 2009).

A implantação destas iniciativas apresenta limitações: (i) falta de recursos financeiros; (ii) pouca ou nenhuma infraestrutura ou expertise; (iii) limitação cultural; e (iv) conflitos entre os atores envolvidos (Nyaupane, Morais, \& Dowler, 2006). Kibicho (2008) entende como benefícios: (i) a inclusão dos agentes envolvidos; (ii) a avaliação dos benefícios individuais e coletivos; (iii) a definição dos objetivos; e (iv) a análise das decisões implantadas. Segundo Briedenhann e Wickens (2004) deve-se considerar que a percepção dos turistas relaciona-se com a avaliação da atitude da comunidade. 0 modo de participação da comunidade influenciará na experiência do turista e o planejamento do turismo afetará a comunidade inteiramente.

Segundo Blackstock (2005), o desenvolvimento comunitário visa transformar as localidades em ativas e sustentáveis assentadas na justiça social e respeito mútuo, pretende-se com isso eliminar barreiras à participação popular e promover uma emancipação coletiva das questões locais. Entretanto, Okazaki (2008) destacam que a participação das comunidades raramente são articuladas, pois para atingir seus objetivos deverá ser acompanhada da redistribuição do poder. Mayaka, Croy e Cox (2018) pontuaram a participação da comunidade como um desejo e não uma característica inerente ao TBC.

O desenvolvimento comunitário é impelido por um imperativo econômico neoliberal na busca de sustentar uma "indústria" do turismo em resposta às novas exigências mercantis. A justiça social e capacitação permanecem em segundo plano, a comunidade é levada a apoiar o fenômeno turístico na ilusão de uma gestão compartilhada, quando na verdade intenciona-se tornar a atividade mais atrativa e aceitável para os moradores (Blackstock, 2005). Essa redistribuição do poder a partir de uma gestão da comunidade estimularia os atores locais, sem depender do governo, empresas privadas e ONGs, a serem responsáveis pela tomada de decisão, ações, controle do desenvolvimento turístico (Timothy, 2007), sendo este o princípio para fugir da massificação do mercado.

Blackstok (2005) afirma que o controle local não levará imediatamente a uma tomada de decisão mais participativa destes atores, pois as comunidades não são homogêneas, e tal estratificação pode gerar uma disputa de poder entre grupos que atuem em beneficio próprio e não pela coletividade. Por isso, Okazaki (2008) defende a utilização de facilitadores - consultores, ONGs e representantes do governo - para construir um relacionamento mais respeitoso na comunidade. Mayaka et al. (2018) possuem uma visão contrária ao declarar haver poucas chances de participação da comunidade quando a iniciativa do TBC se origina de agentes exógenos. Devido a estas questões e a necessidade de capacitação dos locais, a participação da comunidade é pouco estimulada ou restrita à legitimação das decisões por significarem um aumento nos custos e uma diminuição nos lucros (Blackstock, 2005).

Outras questões dificultam o progresso das iniciativas de TBC, ao pesquisar o Turismo Rural Comunitário na América Latina, Maldonado (2009) identificou o despreparo das comunidades, as quais se inseriam na atividade em situações de improviso, com ausência de profissionalismo e desconhecimento dos mercados e dos instrumentos de gestão. Assim, possuíam grande instabilidade e fraca competitividade. Destacam-se duas razões para impedir o avanço do TBC: em primeiro, a ordem socioambiental ao proporcionar um ambiente político-institucional desfavorável às relações de cooperação; em segundo, a ordem metodológica, ou 
seja, o desconhecimento do processo. A superação destas razões somente ocorrerá quando as comunidades, ainda desorganizadas e desestruturadas, souberem lidar com a complexidade da atividade turística, com a promoção do amadurecimento das relações de interesse coletivo e com o suporte dos agentes exógenos (Mielke, 2009).

Bursztyn e Bartholo (2012) destacam que a falta de informações qualificadas e dificuldades de comunicação causa à falência até de projetos bem estruturados, bem como, a falta de estratégias para introduzir estas iniciativas nos mercados turísticos. Sancho e Malta (2015) pedem atenção à relevância demasiada dispensada à escala local de desenvolvimento sob a ameaça de ignorar as várias escalas envolvidas nas relações de poder e nos processos de reconformação dos territórios. Assim, a autonomia não deve ser entendida como autossuficiência, nem acarretar na oclusão das relações exógenas.

Opondo-se ao modelo hegemônico, o TBC não pode ser visto apenas como mais um segmento de mercado, pois ganhos econômicos não representam seu único potencial, (Bursztyn \& Bartholo, 2009). Para Irving (2009), o TBC não é apenas uma comunidade recebendo viajantes à procura do exótico, mas uma oportunidade de experiências compartilhadas. Sendo assim, as discussões sobre a prática devem ser voltadas para suas premissas centrais: (i) base endógena da iniciativa e desenvolvimento local; (ii) participação e protagonismo social no planejamento, implementação e avaliação de projetos turísticos; (iii) escala limitada e impactos sociais e ambientais controlados; (iv) geração de benefícios diretos à população local; (v) afirmação cultural e interculturalidade; e (vi) o "encontro" como condição essencial. Assim, é possível realizar um breve resumo dos construtos dos fundamentos teóricos do TBC, conforme demonstrado no Quadro 2.

Quadro 2 - Construtos dos fundamentos teóricos do TBC

\begin{tabular}{|l|c|}
\hline \multicolumn{1}{|c|}{ Construtos } & Referências \\
\hline Convivencialidade; Experiência & $\begin{array}{c}\text { Briedenhann e Wickens (2004); Gómez et al. (2015); Irving } \\
\text { (2009); Lobato (2013); Sampaio et al. (2014); Sampaio e } \\
\text { Coriolano (2009); Sampaio e Zamignan (2012) }\end{array}$ \\
\hline Valorização da Identidade Cultural & $\begin{array}{c}\text { Sansolo e Bursztyn (2009) } \\
\text { Autogestão; Equidade; Distribuição da Renda }\end{array}$ \\
\hline Protagonismo dos Atores Comunitários & $\begin{array}{c}\text { Fabrino, Nascimento e Costa (2016); Irving (2009); MTUR } \\
\text { (2010) }\end{array}$ \\
\hline Desenvolvimento Sustentável Local; & $\begin{array}{c}\text { Aldecua (2011); Blackstock (2005); Bursztyn e Bartholo } \\
\text { (2009); Fabrino, Nascimento e Costa (2016); Irving (2009); } \\
\text { Mayaka, Croy e Cox (2018); Sampaio e Coriolano (2009); } \\
\text { Sansolo e Bursztyn (2009) }\end{array}$ \\
\end{tabular}

Fonte: Elaborado pelas autoras (2018)

Diante do exposto, para melhor compreender a evolução destes conceitos na produção científica optou-se por realizar um estudo bibliométrico do TBC, na busca de indicar os fundamentos e aspectos mais pesquisados e debatidos nos últimos anos possibilitando assim uma síntese teórica de todo o pensamento reunido acerca do tema, além de demonstrar lacunas teóricas que necessitam ser mais amplamente discutidas em futuras pesquisas.

\section{ANÁLISE DOS RESULTADOS}

\subsection{Estudo bibliométrico do TBC}

Inicialmente, observou-se que 291 autores foram responsáveis pela produção dos 158 artigos analisados, dos quais $70,80 \%$ são escritos em língua espanhola ou portuguesa. A produção em língua inglesa apresentou uma crescente desde o ano de 2013, já os artigos produzidos em espanhol e português são flutuantes no recorte estudado com picos nos anos de 2013 e 2016, atingindo 22\% e 25\% do total de produções respectivamente, conforme demonstrado no Gráfico 1. 


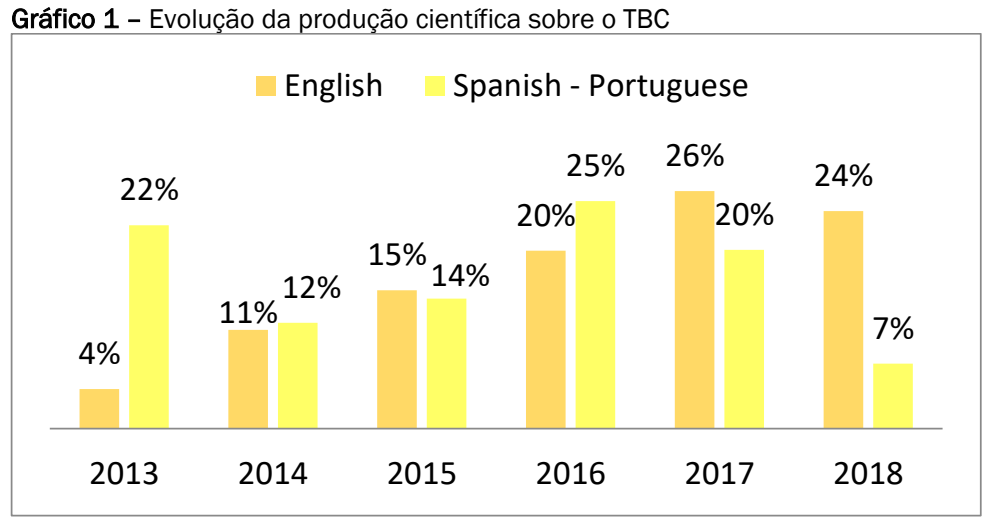

Fonte: Estudo Bibliométrico (2018)

A aplicação da Lei de Lotka revelou os padrões de produtividade dos autores, e relaciona a distribuição dos trabalhos pelo número de autores nas contagens direta e completa (Gráfico 2). A contagem direta credita apenas as contribuições dos autores principais, enquanto na contagem completa é creditada uma contribuição para cada autor (Alvarado, 2002). Observou-se uma grande concentração de autores produzindo apenas um artigo, este quantitativo caiu drasticamente ao avaliar os autores com duas ou mais produções, sendo a diferença mais perceptível na contagem completa.

Gráfico $2-\mathrm{N}^{\circ}$ de autores versus artigos produzidos

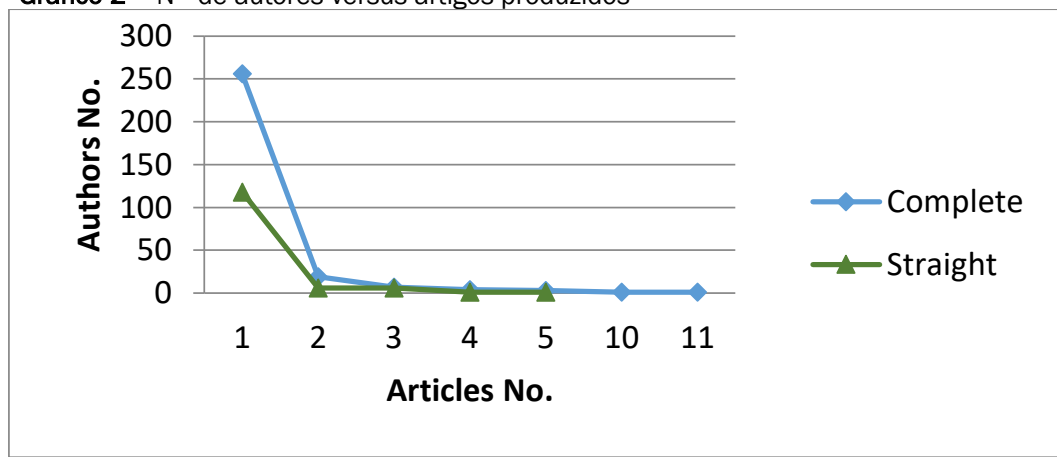

Fonte: Estudo Bibliométrico (2018)

Analisando a produtividade dos autores principais (contagem direta), obteve-se um conjunto de 132 autores, do quais $89 \%$ fizeram somente uma contribuição, sendo este grupo responsável por $74 \%$ dos artigos produzidos. A produtividade média total de autores é de 0,55 , com variância de 0,57 e desvio padrão de 0,75 (Tabela 1).

Tabela 1 - Produtividade e autores pela contagem direta

\begin{tabular}{ccccc}
$\begin{array}{c}\mathrm{N}^{\circ} \text { contribuições por } \\
\text { autor }\end{array}$ & $\mathrm{N}^{\circ}$ autores & \% de autores & $\mathrm{N}^{\circ}$ artigos & \% de artigos \\
\hline 1 & 118 & 0,893939394 & 118 & 0,746835443 \\
2 & 6 & 0,045454545 & 12 & 0,075949367 \\
3 & 6 & 0,045454545 & 18 & 0,113924051 \\
4 & 1 & 0,007575758 & 4 & 0,025316456 \\
6 & 1 & 0,007575758 & 6 & 0,037974684 \\
TOTAL & 132 & 1 & 158 & 1 \\
\hline
\end{tabular}

Fonte: Adaptado de Urbizagastegui (2008) 
Na contagem completa, o universo corresponde a 291 autores, onde 87,9\% publicaram somente um artigo no período, correspondendo a $74,6 \%$ do número acumulado de artigos. Logo, a produtividade média geral é 1,27 artigos por autor, com variância de 1,04 e desvio padrão de 1,02 (Tabela 2).

Tabela 2 - Produtividade e autores pela contagem completa

\begin{tabular}{ccccc}
$\begin{array}{c}\mathrm{N}^{\circ} \text { contribuições por } \\
\text { autor }\end{array}$ & $\mathrm{N}^{\circ}$ autores & \% de autores & $\begin{array}{c}\mathrm{N}^{\circ} \text { acumulado de } \\
\text { artigos }\end{array}$ & \% de artigos \\
\hline 1 & 256 & 0,879725086 & 118 & 0,746835443 \\
2 & 19 & 0,065292096 & 6 & 0,037974684 \\
3 & 7 & 0,024054983 & 18 & 0,113924051 \\
4 & 4 & 0,013745704 & 1 & 0,006329114 \\
5 & 3 & 0,010309278 & 7 & 0,044303797 \\
10 & 1 & 0,003436426 & 2 & 0,012658228 \\
11 & 1 & 0,003436426 & 6 & 0,037974684 \\
Total & 291 & 1 & 158 & 1 \\
\hline
\end{tabular}

Fonte: Adaptado de Urbizagastegui (2008)

Observou-se que um grupo de 14 autores foi o mais produtivo, sendo responsáveis por $25 \%$ dos artigos. Esse grupo é composto por pesquisadores da África do Sul, Brasil, Equador, Espanha e México, com 57\% de pesquisadores brasileiros. Por fim, detectou-se um elevado número de pequenos produtores, caracterizando uma disciplina em expansão como explica Urbizagastegui (2008).

A Lei de Bradford identificou os periódicos mais relevantes para o tema. Na amostra, detectou-se um universo de 64 revistas científicas publicando sobre o TBC divididas por três zonas de produtividade (núcleo, zona 2 e zona 3), com $\mathrm{Bm}_{\mathrm{m}}=4$. As duas primeiras zonas contêm $66 \%$ dos artigos produzidos, publicados em 15 revistas diferentes, os 34\% restantes estão distribuídos por 49 revistas (Tabela 3).

Tabela 3 - Zonas de produtividade

\begin{tabular}{ccccccc}
\hline $\begin{array}{c}\text { Periódicos } \\
(\mathrm{P})\end{array}$ & $\begin{array}{c}\text { Artigos } \\
(\mathrm{A})\end{array}$ & $\begin{array}{c}\mathrm{P}+\text { (acumu- } \\
\text { lado) }\end{array}$ & $\begin{array}{c}\text { A+ (acumu- } \\
\text { lado) }\end{array}$ & Ln ( P+ ) & P*A & $\begin{array}{c}\text { Zona de Produ- } \\
\text { tividade }\end{array}$ \\
\hline 1 & 23 & 1 & 23 & 0 & 23 & \\
1 & 20 & 24 & 43 & 1,380211 & 20 & Núcleo \\
1 & 10 & 21 & 53 & 1,322219 & 10 & \\
\hline 1 & 7 & 11 & 60 & 1,041393 & 7 & \\
1 & 6 & 8 & 66 & 0,90309 & 6 & \\
2 & 5 & 8 & 71 & 0,90309 & 10 & Zona 2 \\
4 & 4 & 9 & 75 & 0,954243 & 16 & \\
4 & 3 & 8 & 78 & 0,90309 & 12 & \\
\hline 5 & 2 & 8 & 80 & 0,90309 & 10 & Zona 3 \\
44 & 1 & 46 & 81 & 1,662758 & 44 & \\
\hline
\end{tabular}

Fonte: Estudo Bibliométrico (2018).

O crescimento do número acumulado de artigos $(\mathrm{A}+)$ pelo crescimento do número acumulado de periódicos $(\mathrm{P}+)$ corresponde a uma constante logarítmica. Logo, o gráfico da função logarítmica do número acumulado de periódicos ( $(\mathrm{n} \mathrm{P}+)$ equivale à comprovação gráfica da Lei de Bradford, que apresenta um rápido crescimento na base, passando por uma constante e chegando a estagnação (Sudhier, 2014). No gráfico 3, há 
um crescimento acelerado na base e o começo de uma constante, sem atingir a estagnação, pois o TBC é uma área de estudo recente.

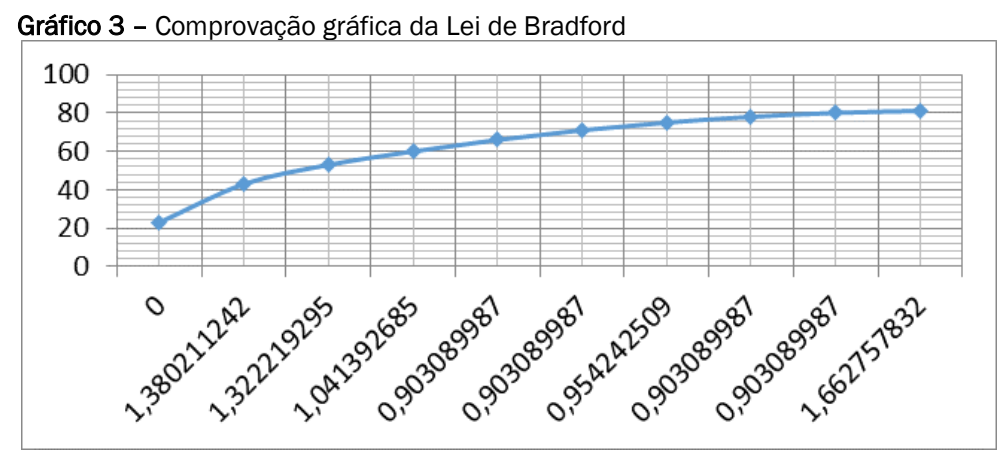

Fonte: Estudo Bibliométrico (2018)

A dispersão de artigos por periódicos verifica-se no Gráfico 4. O Brasil possui os dois periódicos mais produtivos, o terceiro é oriundo da África do Sul, constatando um maior interesse científico sobre o tema em países em vias de desenvolvimento, onde há maior concentração de iniciativas do TBC.

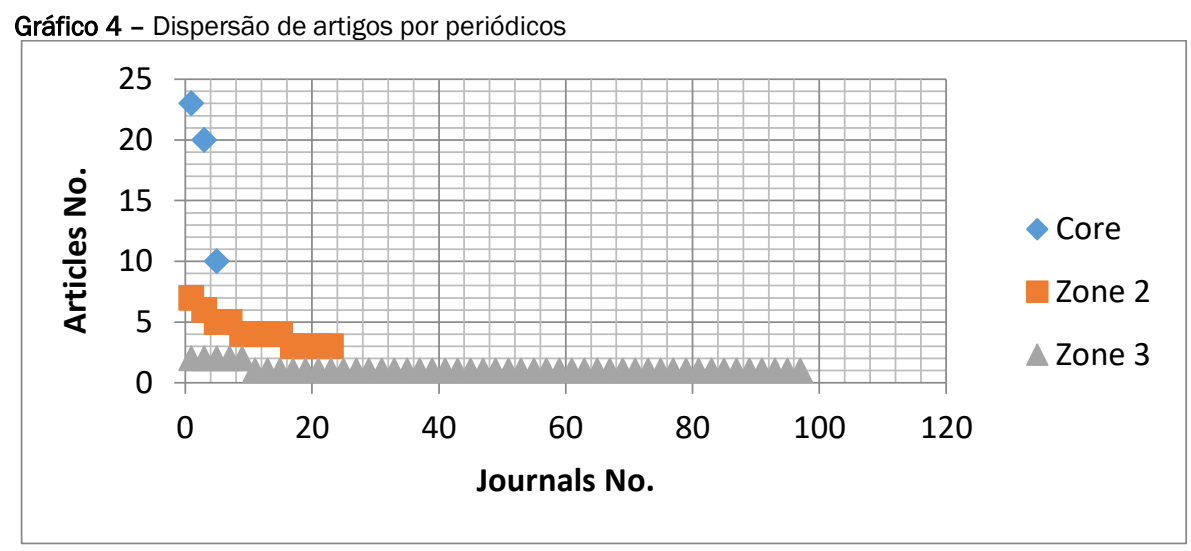

Fonte: Estudo Bibliométrico (2018)

A Lei de Zipf foi aplicada com auxílio de um software de Análise de Conteúdo para contar a frequência das palavras. Analisou-se aproximadamente 621 mil palavras, elencadas do maior número de ocorrência para o menor, e a partir das palavras de maior frequência, elaborou-se a nuvem de palavras da Figura 2.

Figura 2 - Frequência da lei de Zipf law

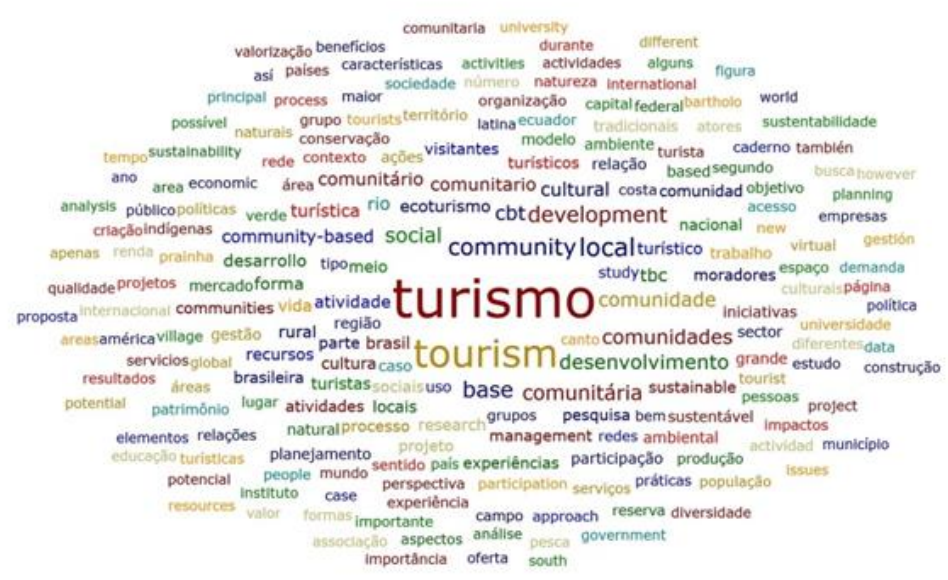

Fonte: Estudo Bibliométrico (2018) 
Analisando a nuvem de palavras, identificaram-se os termos comuns para esta área de conhecimento, tais como turismo, base local, comunidade, moradores, cultura, território, conservação, entre outros. Entretanto, percebe-se que aspectos importantes para o sucesso das iniciativas não possuíram destaque na análise, termos como governança, participação, comercialização, promoção, divulgação, marketing não possuem grande frequência nas produções estudadas, demonstrando uma possível lacuna teórica a ser explorada pelos pesquisadores.

Avaliou-se a disseminação do conhecimento através dos artigos e periódicos mais citados. Notando-se um total de 464 citações, distribuídas por 64 periódicos, apenas 17 artigos foram responsáveis por 56\% das citações (Quadro 4), porém, se percebeu que 47\% dos artigos nunca foram citados, dentre estes 57\% são oriundos de revistas científicas nacionais. Os treze periódicos com mais artigos contemplam $63 \%$ do total de citações das produções analisadas, sendo a Tourism Management a revista mais citada, seguida do Caderno Virtual de Turismo e Estudios y Perspectivas en Turismo, respectivamente (Quadro 3).

Quadro 3 - Periódicos mais citados

\begin{tabular}{|c|c|c|c|c|}
\hline Periódico & $\mathrm{N}^{\circ}$ artigos & $\%$ artigos & Citações & \% citações \\
\hline Caderno Virtual de Turismo & 23 & $16 \%$ & 42 & $9 \%$ \\
\hline Revista Brasileira de Turismo & 20 & $14 \%$ & 12 & $3 \%$ \\
\hline $\begin{array}{c}\text { African Journal of Hospitality, Tourism } \\
\text { and Leisure }\end{array}$ & 10 & $7 \%$ & 6 & $1 \%$ \\
\hline Estudios y Perspectivas em Turismo & 7 & $5 \%$ & 40 & $9 \%$ \\
\hline El Periplo Sustentable & 6 & $4 \%$ & 24 & $5 \%$ \\
\hline $\begin{array}{c}\text { PASOS Revista de Turismo y Patrimonio } \\
\text { Cultural }\end{array}$ & 5 & $3 \%$ & 23 & $5 \%$ \\
\hline Revista de Cultura e Turismo & 4 & $3 \%$ & 10 & $2 \%$ \\
\hline Gazeta de Antropologia & 4 & $3 \%$ & 11 & $2 \%$ \\
\hline Revista Iberoamericana de Turismo & 4 & $3 \%$ & 5 & $1 \%$ \\
\hline Anais Brasileiros de Estudos Turísticos & 4 & $3 \%$ & 3 & $1 \%$ \\
\hline Tourism Management & 3 & $2 \%$ & 66 & $15 \%$ \\
\hline Sustainability & 3 & $2 \%$ & 30 & $7 \%$ \\
\hline $\begin{array}{c}\text { Worldwide Hospitality and Tourism } \\
\text { Themes }\end{array}$ & 2 & $1 \%$ & 21 & $5 \%$ \\
\hline
\end{tabular}

Fonte: Estudo Bibliométrico (2018)

Observando os autores dos artigos mais citados (Quadro 4), identificou-se que estas pesquisas eram originárias de países como Austrália, Brasil, Colômbia, Equador, Espanha, Estados Unidos, Indonésia, Laos, Malásia e México. Os dois artigos mais citados são oriundo de pesquisadores procedentes de universidades australianas, mas não foram detectados entre elas grupos de discussão sobre o TBC, sendo o grande número de citações devido a sua publicação em revistas de alto impacto. Os pesquisadores brasileiros contribuíram com cinco artigos, alguns destes autores são referências reconhecidas nas pesquisas sobre o TBC, e transitam em grupos de pesquisa dedicados ao tema.

Quadro 4 - Artigos mais citados
\begin{tabular}{|l|c|c|c|c|c|}
\hline Título & Autores & Periódicos & Ano & Citações & $\%$ \\
\hline $\begin{array}{l}\text { Strengthening Community-Based Tourism in } \\
\text { a new resource-based island nation: Why } \\
\text { and how? }\end{array}$ & $\begin{array}{c}\text { D. Tolkach } \\
\text { B. King }\end{array}$ & $\begin{array}{c}\text { Tourism Manage- } \\
\text { ment }\end{array}$ & 2015 & 49 & $11 \%$ \\
\hline $\begin{array}{l}\text { Touring responsibility: The trouble with 'go- } \\
\text { ing local' in community-based tourism in } \\
\text { Thailand }\end{array}$ & $\begin{array}{c}\text { H. L. Sin } \\
\text { Minca }\end{array}$ & C. Geoforum & 2014 & 34 & $8 \%$ \\
\hline $\begin{array}{l}\text { An Integrated Approach to "Sustainable } \\
\text { Community-Based Tourism" }\end{array}$ & $\begin{array}{c}\text { T. B. Dangi } \\
\text { T. Jamal }\end{array}$ & Sustainability & 2016 & 28 & $6 \%$ \\
\hline
\end{tabular}


Quadro 4 - Artigos mais citados

\begin{tabular}{|c|c|c|c|c|c|}
\hline & & & & & \\
\hline Título & Autores & Periódicos & Ano & Citações & $\%$ \\
\hline $\begin{array}{l}\text { Os conflitos em torno do turismo comunitá- } \\
\text { rio na Prainha do Canto Verde (CE) }\end{array}$ & $\begin{array}{l}\text { R.A. Fortunato } \\
\text { L.S. Silva }\end{array}$ & $\begin{array}{l}\text { Revista Brasileira de } \\
\text { Ecoturismo }\end{array}$ & 2013 & 17 & $4 \%$ \\
\hline $\begin{array}{l}\text { Community-building and amenity migration } \\
\text { in community-based tourism development. } \\
\text { An approach from southwest Spain }\end{array}$ & $\begin{array}{l}\text { E. Ruiz-Ballesteros } \\
\text { R. Cáceres-Feria }\end{array}$ & $\begin{array}{l}\text { Tourism Manage- } \\
\text { ment }\end{array}$ & 2016 & 16 & $4 \%$ \\
\hline $\begin{array}{l}\text { Turismo de Base Comunitária no Brasil. In- } \\
\text { sustentabilidade é uma Questão de Ges- } \\
\text { tão? }\end{array}$ & $\begin{array}{l}\text { E.J.C. Mielke } \\
\text { F.V. Pegas }\end{array}$ & $\begin{array}{l}\text { Revista Turismo em } \\
\text { Análise }\end{array}$ & 2013 & 13 & $3 \%$ \\
\hline $\begin{array}{l}\text { Barriers to Local Residents' Participation in } \\
\text { Community-Based Tourism: Lessons from } \\
\text { Houay Kaeng Village in Laos }\end{array}$ & $\begin{array}{l}\text { K. Sangkyun } \\
\text { P. Eerang P. } \\
\text { Toulakham }\end{array}$ & $\begin{array}{l}\text { SHS Web of Confe- } \\
\text { rences }\end{array}$ & 2014 & 12 & $3 \%$ \\
\hline $\begin{array}{l}\text { Turismo comunitario en Ecuador: ¿quo } \\
\text { vadis? }\end{array}$ & C. G. Palacios & $\begin{array}{l}\text { Estudios y Pers- } \\
\text { pectivas en Tu- } \\
\text { rismo }\end{array}$ & 2014 & 12 & $3 \%$ \\
\hline $\begin{array}{l}\text { El turismo comunitario en la Sierra Norte de } \\
\text { Oaxaca: perspectiva desde las institucio- } \\
\text { nes y la gobernanza en territorios indígenas }\end{array}$ & $\begin{array}{l}\text { B. P. Villavicencio } \\
\text { J. G. Zamora } \\
\text { G. L. Pardo }\end{array}$ & $\begin{array}{l}\text { El Periplo Sustenta- } \\
\text { ble }\end{array}$ & 2016 & 11 & $2 \%$ \\
\hline $\begin{array}{l}\text { Os desafios do turismo no contexto da sus- } \\
\text { tentabilidade: as contribuições do turismo } \\
\text { de base comunitária }\end{array}$ & $\begin{array}{l}\text { A. Burgos } \\
\text { F. Mertens }\end{array}$ & $\begin{array}{l}\text { PASOS Revista de } \\
\text { Turismo y Patrimo- } \\
\text { nio Cultural }\end{array}$ & 2015 & 11 & $2 \%$ \\
\hline $\begin{array}{l}\text { Tourism cooperative for scaling up commu- } \\
\text { nity-based tourism }\end{array}$ & $\begin{array}{l}\text { V. Nair } \\
\text { N. H. Mohamad } \\
\text { A. Hamzah }\end{array}$ & $\begin{array}{l}\text { Worldwide Hospital- } \\
\text { ity and Tourism } \\
\text { Themes }\end{array}$ & 2013 & 11 & $2 \%$ \\
\hline $\begin{array}{l}\text { Rise and fall of community-based tourism - } \\
\text { facilitators, inhibitors and outcomes }\end{array}$ & $\begin{array}{l}\text { A. D. A. Tasci R. } \\
\text { Croes } \\
\begin{array}{l}\text { B. Villanueva }\end{array}\end{array}$ & $\begin{array}{l}\text { Worldwide Hospital- } \\
\text { ity and Tourism } \\
\text { Themes }\end{array}$ & 2014 & 10 & $2 \%$ \\
\hline $\begin{array}{l}\text { Turismo de base comunitária em territórios } \\
\text { rurais: caso da Associação de Agroturismo } \\
\text { Acolhida na Colônia (SC) }\end{array}$ & $\begin{array}{l}\text { T. C. Guzzatti C. } \\
\text { A. C. Sampaio L. } \\
\text { N. M. T. Coriolano }\end{array}$ & $\begin{array}{l}\text { Revista Brasileira de } \\
\text { Ecoturismo }\end{array}$ & 2013 & 9 & $2 \%$ \\
\hline $\begin{array}{l}\text { Host-Guest Orientations of Community- } \\
\text { based Tourism Products: A Case Study in } \\
\text { Bali, Indonesia }\end{array}$ & $\begin{array}{l}\text { N. M. Ernawati } \\
\text { D. Sanders } \\
\text { R. Dowling }\end{array}$ & $\begin{array}{l}\text { International Jour- } \\
\text { nal of Tourism Re- } \\
\text { search }\end{array}$ & 2017 & 7 & $2 \%$ \\
\hline $\begin{array}{l}\text { Energias Renovables y Turismo Comunita- } \\
\text { rio: Una apuesta conjunta para el desarrollo } \\
\text { humano sostenible de las comunidades ru- } \\
\text { rales }\end{array}$ & T. J. Castilla & Energética & 2014 & 7 & $2 \%$ \\
\hline $\begin{array}{l}\text { Impactos culturales del turismo comunita- } \\
\text { rio en Ecuador sobre el rol del Chamán y los } \\
\text { ritos mágico-religiosos }\end{array}$ & E. Cabanilla & $\begin{array}{l}\text { Estudios y Perspec- } \\
\text { tivas en Turismo }\end{array}$ & 2015 & 7 & $2 \%$ \\
\hline $\begin{array}{l}\text { La valoración del diálogo en la construcción } \\
\text { e implementación de rutas turísticas: Pro- } \\
\text { yectos Palacios de Rio y Central de Turismo } \\
\text { Comunitario de la Amazonia - Brasil }\end{array}$ & $\begin{array}{l}\text { M. Egrejas } \\
\text { I. Bursztyn } \\
\text { R. S. Bartholo }\end{array}$ & $\begin{array}{l}\text { Estudios y Perspec- } \\
\text { tivas en Turismo }\end{array}$ & 2013 & 7 & $2 \%$ \\
\hline
\end{tabular}

Fonte: Estudo Bibliométrico (2018) 
A bibliometria revelou que o TBC é uma área de conhecimento ainda em fase inicial de crescimento, pois a produção encontrar-se pulverizada num grande número de periódicos com diversos autores de poucos artigos. 0 estudo também revela um número pequeno de especialistas sobre o tema, responsáveis por grande parte da produção sobre o assunto, concentrada em poucos periódicos. Além disso, o EB apontou possíveis lacunas teóricas a serem exploradas.

\subsection{Interpretação e síntese dos fundamentos teóricos}

Os artigos selecionados para a RIL foram os mais citados no recorte pesquisado. Além destes, selecionaramse outros 03 artigos que abordavam aspectos ainda pouco debatidos nos estudos sobre o TBC, pois discorrem sobre a comercialização e a viabilidade das iniciativas, possíveis lacunas teóricas do tema. Atingindo-se um total de 20 artigos para a síntese do conhecimento.

Quanto aos métodos, prevaleceu a pesquisa qualitativa, sendo a abordagem mais utilizada o estudo de caso. Priorizou-se também a observação e a entrevista como técnicas de coleta, somente um dos artigos adotou o método quantitativo. Os tipos de amostra mais frequentes foram a intencional, seguida da bola de neve. Os casos estudados concentraram-se em países da África, Ásia, e América Latina como anteriormente observado por López-Guzmán; Sánchez-Cañizares e Pavón (2011).

O principal tema na maioria dos artigos girou acerca da participação da comunidade, corroborado por estudos como os de Kibicho (2008) e Okazaki (2008) que apontam a participação como elemento essencial para o TBC. Kim, Park e Phandanouvong (2014) apontaram os baixos níveis de educação, as más condições de vida, pouco ou nenhum aporte financeiro, as disparidades de poder, a desconfiança nas autoridades, a falta de conhecimento sobre o turismo e a visão deste como algo sazonal que fornece pouca renda, como barreiras à participação de residentes no planejamento e execução da atividade em países em desenvolvimento.

Outro estudo relatou os conflitos internos entre os atores, ainda que o TBC se apresente como uma ferramenta para o desenvolvimento (Palacios, 2016), confirmando as ideias de Nyaupane, Morais e Dowler (2006). Para Ruiz-Ballesteros e Cáceres-Feria (2016), iniciar a discussão sobre o conceito de comunidade pode influenciar numa melhor base para o planejamento e a operação da atividade. A distinção de conceitos já foi anteriormente abordada por Aldecua (2011), que distinguiu a definição entre TBC e EBC, bem como, Alves (2013) e Silva, Malta e Sá (2016) ao identificar os pontos discrepantes nos conceitos de TBC e TC.

O TBC evidenciou-se como uma atividade não homogênea restrita a alguns participantes, quando deveria envolver toda a comunidade, sendo este fator causa das divergências entre seus membros (Fortunato \& Silva, 2013). A heterogeneidade do fenômeno, razão de disputas internas, também foi demonstrada por Blackstock (2005). Ressaltou-se a importância da gestão participativa, pois "o TBC não deveria ser tratado como uma panaceia para o desenvolvimento das comunidades nem para a busca de tão sonhada sustentabilidade, e sim como uma oportunidade de desenvolvimento para uma comunidade organizada" (Burgos \& Mertens, 2015:68).

Alguns estudos propuseram formas de integrar os atores, Tolkach e King (2015) discutem sobre a formação de uma rede nacional do TBC para apoiar o desenvolvimento e auxiliar no enfretamento de desafios como a falta de informação, o financiamento e o marketing. As redes para ter sucesso precisam de uma boa comunicação, além de manter o equilíbrio do poder. Cooperativas surgem como opções para aumentar o envolvimento das comunidades, sendo responsáveis pelo gerenciamento das questões econômicas, socioculturais e ambientais; contribuindo para o fortalecimento do senso da coesão social (Nair, Mohamad, \& Hamzah, 2013).

A sustentabilidade foi amplamente debatida no recorte, pois como lembraram Dangi e Jamal (2016) ela possui uma proximidade com o TBC em definições, critérios e princípios, como já abordaram Irving e Azevedo (2002) e Sampaio e Coriolano (2009). O uso de energias renováveis nas iniciativas, além de servir como atrativos, pode gerar mais empregos, embora o conceito de sustentabilidade seja pouco considerado na práxis da política pública. 0 ideal de sustentabilidade também serve de atrativo para o turismo responsável, 
e apesar da estreita relação com o TBC, a pesquisa realizada por Sin e Minca (2014) demonstram uma hierarquia entre os que ajudam (a turista) e os que são ajudados (a comunidade).

As "viagens muitas vezes se tornam um imbróglio de distanciamento e envolvimento, de proteção paternalista e exploração mútua, de generosidade e hospitalidade, mas também de corrupção e interesse próprio" (Sin \& Minca, 2014:96). Logo, o TBC almeja preservar o singular, o autêntico e os valores comunitários, Cabanilla (2015) observou os impactos culturais negativos da atividade, quando os atores locais assumem uma postura mais mercantil para agradar o turista, e se aproximam do conceito de TC tratado por Alves (2013) e Silva, Malta e Sá (2016).

A comercialização foi discutida a partir do marketing colaborativo dos destinos e do branding, concluindo que a ausência de plano nesta área prejudica o processo de acesso ao mercado (Tasci, Croes, \& Villanueva, 2014). Esta dificuldade de acesso ao mercado foi anteriormente estudada por Bursztyn e Bartholo (2012) e Mielke (2009), apontando-a como caminho para o sucesso das iniciativas, sendo a falta dessas estratégias a principal causa do fracasso de muitas iniciativas. Cañada (2016) identificou duas formas de acesso ao mercado: (i) orientada para a classe média e baixa do marcado local e nacional, e (ii) a busca por integrar o mercado internacional, sendo a primeira mais exitosa. Andreu, Tur e De La Rosa (2017) destacam que da viabilidade dependerá a abertura para o mercado, e da capacidade dos atores em lidar com as tensões. 0 contato direto com o turista facilita a comercialização, mas a dependência das redes pode reduzir a autonomia comunitária (Cabanilla \& Gentili, 2015).

O planejamento e a governança servem para superar os desafios como: relações de poder, processos de gestão e organização da atividade, profissionalização, posicionamento de mercado e manter sua organização produtiva sem sucumbir às exigências do mercado (Egrejas, Bursztyn, \& Bartholo, 2013; Guzzatti, Alberto, Sampaio, Neide, \& Teixeira, 2013; Villavicencio, Zamora, \& Pardo, 2016), mas sem maior profundidade conceitual.

Logo, percebeu-se pouca ou nenhuma evolução do conhecimento nos últimos cinco anos, pois as dificuldades apresentadas nos artigos pesquisados já haviam sido descritas anteriormente, e as pesquisas mais recentes somente apontam os mesmos desafios de outrora sem aprofundar discussões e propor soluções. A principal causa dos conflitos e problemas da comunidade provém da dificuldade de interação entre os atores envolvidos, e isto se reflete como uma questão de governança, mas mesmo sabendo como corrigir não se identificou um estudo que se aventurasse a propor melhorias. Pesquisas relacionadas à demanda, à comercialização e ao acesso ao mercado são incipientes. Os estudos analisados foram intencionalmente escolhidos para demonstrar como o assunto é explanado. A fim de sumarizar os achados deste estudo, desenvolveu-se o Quadro 5.

Quadro 5 - Principais achados teóricos e metodológicos

\begin{tabular}{|c|c|}
\hline Achados teóricos & Autores \\
\hline Participação da população local & $\begin{array}{c}\text { Burgos e Mertens (2015); Fortunato e Silva (2013); Kim, Park e } \\
\text { Phandanouvong (2014); Ruiz-Ballesteros e Cáceres-Feria } \\
\text { (2016); Tolkach e King (2015) }\end{array}$ \\
\hline Sustentabilidade & $\begin{array}{l}\text { Burgos e Mertens (2015); Castilla (2014); Dangi e Jamal } \\
\text { (2016) }\end{array}$ \\
\hline Governança, Redes e Cooperativas & $\begin{array}{c}\text { Burgos e Mertens (2015); Mielke e Pegas (2013); Nair, } \\
\text { Mohamad e Hamzah (2013); Sampaio (2013); Tolkach e King } \\
\text { (2015) Villavicencio, Zamora e Pardo (2016) }\end{array}$ \\
\hline Turismo Responsável & Dangi e Jamal (2016); Sin e Minca (2014) \\
\hline Planejamento & $\begin{array}{c}\text { Egrejas, Burstyn e Bartholo (2013); Guzzatti, Sampaio e } \\
\text { Coriolano (2013); Palacios (2016) }\end{array}$ \\
\hline Comercialização e acesso ao mercado & $\begin{array}{c}\text { Andreu, Tur e De La Rosa (2017); Cañada (2016); Tasci, Croes } \\
\text { e Villanueva (2014) }\end{array}$ \\
\hline
\end{tabular}

Fonte: Elaborado pelas autoras (2018)

\section{CONSIDERAÇÕES FINAIS}

O estudo através do EB comprovou as leis de Lotka, Bradford e Zipf e pesquisou a disseminação do conhecimento. A produção científica sobre o TBC encontra-se em escalada crescente mundial, porém o mesmo 
não acontece no cenário brasileiro. Os artigos mais citados provêm de periódicos com maiores classificações e fator de impacto, sendo priorizada a difusão do conhecimento em revistas de maior renome, ainda que nem todos os autores sejam especialistas no tema.

A RIL constatou que as produções sobre o tema se limitam a informar os obstáculos no processo de gestão do TBC, desde questões internas da comunidade até os conflitos e desconfianças com os agentes externos, e apesar de apontarem uma boa governança como uma possível solução, as pesquisas deixam a desejar na proposição de metodologias que auxiliem neste processo. A comercialização do TBC foi apontada como uma dificuldade, mas os estudos não discorrem sobre o plano de marketing das iniciativas, sendo possível afirmar que o discurso sobre a melhoria da qualidade de vida, emancipação social e desenvolvimento local sustentável superam o debate sobre o produto. Entretanto, mesmo o TBC adotando os princípios da sustentabilidade ainda tem entre suas funções gerar renda, e sem este preceito, não serão obtidos os ideais que Ihe servem de suporte.

A governança também surge como um aspecto a ser melhorado nas comunidades para garantir uma gestão da atividade mais fecunda. Sem dúvida, uma solução para esta questão deverá antevir as soluções de comercialização e acesso ao mercado. A governança deverá ser trabalhada desde o momento da conscientização da população local para o turismo, porém, esse inconveniente se deve também à desconfiança de algumas comunidades com os agentes externos, principalmente, por alguns utilizarem as benesses do TBC como forma de adentrar na comunidade e lucrar com sua autenticidade, por vezes, eximindo da comunidade a autogestão da atividade.

Entender a distinção entre os conceitos de Turismo de Base Comunitária (TBC) e Turismo Comunitário (TC) será primordial. Ambos prometem melhoria da qualidade de vida e geração de renda para a população através do turismo, mas o primeiro se caracteriza por ser uma proposta de emancipação comunitária, no qual a atividade será autogerida, sendo dela a responsabilidade pelas decisões sobre o fenômeno. Enquanto o TC configura-se como um segmento, que fornece um atrativo autêntico e peculiar ao turista, mas pelo mercado convencional. Assim, foram identificadas lacunas teóricas na produção científica, que se investigadas contribuirão para o fortalecimento das iniciativas de TBC no mercado turístico.

\section{REFERÊNCIAS}

Albuquerque, M. C. F. de. (2016). Modelo de análise da governança do TBC : uma proposição adaptativa a partir de diversos olhares. Universidade Federal de Pernambuco.

Aldecua, M. J. F. (2011). Turismo comunitario y empresas de base comunitaria turísticas: ¿estamos hablando de lo mismo? El Periplo Sustentable, 20(1), 31-74. Retrieved from http://www.redalyc.org/pdf/1934/193417856003.pdf

Alvarado, R. U. (2002). A Lei de Lotka na bibliometria brasileira. Ciência da Informação, 31(2), 6. https://doi.org/10.1590/S0100-19652002000200002

Alves, K. (2013). Turismo de Base Comunitária: funtamento histórico e abordagens conceituais. In: Silva, F. P. da (Ed.), Turismo de base comunitária: articulando pesquisa e ensino no Cabula e entorno (1st ed., pp. 81-92). Salvador: EDUNEB.

Andreu, H. G., Tur, A. A., \& De La Rosa, J. U. (2017). ¿Es viable a largo plazo el turismo comunitario? Lecciones aprendidas del caso de Prainha do Canto Verde (Brasil). Gazeta de Antropologia, 33(1), 1-14. Retrieved from http://hdl.handle.net/10481/44378

Araújo, C. A. (2006). Bibliometria: evolução histórica e questões atuais. Em Questão, 12(1), 11-32. https://doi.org/10.19132/1808-5245121.

Bartholo, R., Sansolo, D. G., \& Bursztyn, I. (2009). Apresentação. In: R. Bartholo, D. G. Sansolo, \& I. Bursztyn (Eds.), Turismo de base comunitária: diversidade de olhares e experiências brasileiras (1st ed., pp. 13-21). Rio de Janeiro: Letra e Imagem.

Blackstock, K. (2005). A critical look at community based tourism. Community Development Journal, 40(1), 39-49. https://doi.org/10.1093/cdj/bsi005 
Briedenhann, J., \& Wickens, E. (2004). Tourism routes as a tool for the economic development of rural areasvibrant hope or impossible dream? Tourism Management, 25(1), 71-79. https://doi.org/10.1016/S0261$\underline{5177(03) 00063-3}$

Burgos, A., \& Mertens, F. (2015). Os desafios do turismo no contexto da sustentabilidade : as contribuições do turismo de base comunitária. Pasos, 13(1), 57-71. https://doi.org/10.25145/j.pasos.2015.13.004

Bursztyn, I., \& Bartholo, R. (2009). Turismo para quem? Sobre caminhos de desenvolvimento e alternativas para o turismo no Brasil. In R. Bartholo, D. G. Sansolo, \& I. Bursztyn (Eds.), Turismo de base comunitária: diversidade de olhares e experiências brasi_leiras (pp. 76-91). Rio de Janeiro: Letra e Imagem.

Bursztyn, I., \& Bartholo, R. (2012). O processo de comercialização do turismo de base comunitária no Brasil: desafios, potencialidades e perspectivas. Sustentabilidade Em Debate, 3(1), 97-116. https://doi.org/10.18472/SustDeb.v3n1.2012.7198

Cabanilla, E. (2015). Impactos Culturales Del Turismo Comunitario En Ecuador Sobre El Rol Del Chamán Y Los Ritos Mágico-Religiosos. Estudios y Perspectivas En Turismo Volumen, 24, 356-373.

Cabanilla, E., \& Gentili, J. (2015). Características de las páginas de la Internet de turismo comunitario en países de América. Una aproximación desde el análisis de contenidos y la cartografía temática. Pasos Revista de Turismo y Patrimonio Cultural, 13(1), 157-174. https://doi.org/10.25145/i.pasos.2015.13.011

Cañada, E. (2016). La comercialización del turismo comunitario en América Latina. Anuario de Estudios Centroamericanos, 41(November 2015), 159-189. https://doi.org/10.15517/aeca.v41i1.21845

Castilla, T. J. (2014). Energías renovables y turismo comunitario: una apuesta conjunta para el desarrollo humano sostenible de las comunidades rurales. Energética, 1(44), 93-105. https://doi.org/10.15446/energetica

Coriolano, L. N. M. T. (2009). Turismo comunitário no nordeste brasileiro. In: R. Bartholo, D. G. Sansolo, \& I. Bursztyn (Eds.) Turismo de base comunitária: diversidade de olhares e experiências brasileiras. (pp. 277 288). Rio de Janeiro: Letra e Imagem.

Dangi, T. B., \& Jamal, T. (2016). An integrated approach to "sustainable community-based tourism." Sustainability (Switzerland), 8(5). https://doi.org/10.3390/su8050475

Egrejas, M., Bursztyn, I., \& Bartholo, R. (2013). La valoración del diálogo en la construcción e implementación de rutas turísticas: proyectos Palacios de Rio y Central de Turismo Comunitario de la Amazonia - Brasil. Estudios y Perspectivas En Turismo, 22(6), 1160-1181. Retrieved from http://www.redalyc.org/articulo.oa?id=180729918008

Fabrino, N. H. (2013). Turismo de base comunitária: dos conceitos às práticas e das práticas aos conceitos (Universidade de Brasília). Retrieved from http://repositorio.unb.br/handle/10482/14215

Fabrino, Nathália Hallack, Costa, H. A., \& Nascimento, E. P. do. (2012a). Turismo de Base Comunitária (TBC): elementos chaves para aferir seu desempenho na perspectiva da sustentabilidade. Revista Brasileira de Ecoturismo, 5(3), 546-559. https://doi.org/10.18472/cvt.16n3.2016.1178

Fabrino, Nathália Hallack, Costa, H. A., \& Nascimento, E. P. do. (2012b). Turismo de Base Comunitária (TBC): elementos chaves para aferir seu desempenho na perspectiva da sustentabilidade. Revista Brasileira de Ecoturismo, 5(3), 546-559. https://doi.org/10.34024/rbecotur.2012.v5.6224

Fabrino, Nathália Hallack, Nascimento, E. P. do, \& Costa, helena A. (2016). Turismo de Base Comunitária : uma reflexão sobre seus conceitos e práticas. Caderno Virtual de Turismo, 16(3), 172-190. https://doi.org/10.18472/cvt.16n3.2016.1178

Fortunato, R. Â., \& Silva, L. S. (2013). Os conflitos em torno do turismo comunitário na Prainha do Canto Verde (CE). Revista Brasileira de Ecoturismo, 6(1), 123-138. https://doi.org/10.34024/rbecotur.2019.v12.9449

Gómez, C. R. P., Falcão, M. C., Castillo, L. A. G., Correia, S. N., \& Oliveira, V. M. (2015). Turismo de Base Comunitária como Inovação Social : congruência entre os constructos. PASOS. Revista de Turismo y Patrimonio Cultural, 13(5), 1213-1227. https://doi.org/10.25145/j.pasos.2015.13.082

Guzzatti, T. C., Alberto, C., Sampaio, C., Neide, L., \& Teixeira, M. (2013). Turismo de base comunitária em territórios rurais : caso da Associação de Agroturismo Acolhida na Colônia ( SC ). Revista Brasileira de Ecoturismo, 6(1), 93-106. https://doi.org/10.34024/rbecotur.2013.v6.6230 
Guzzatti, T. C., Sampaio, C. A. C., \& Coriolano, L. N. M. T. (2013). Turismo de base comunitária em territórios rurais : caso da Associação de Agroturismo Acolhida na Colônia ( SC ). Revista Brasileira de Ecoturismo, 6(1), 93-106. https://doi.org/10.34024/rbecotur.2013.v6.6230

Hall, C. M. (2011). Publish and perish? Bibliometric analysis, journal ranking and the assessment of research quality in tourism. Tourism Management, 32(1), 16-27. https://doi.org/10.1016/j.tourman.2010.07.001

Hallack, N., Burgos, A., \& Carneiro, D. M. R. (2011). Turismo de base comunitaria: estado da arte e experiencias brasileiras. Ambientalmente Sustentable, I(11-12), 7-25. Retrieved from http://hdl.handle.net/2183/11979

Irving, M. D. A. (2009). Reinventando a reflexão sobre turismo de base comunitária: inovar é possível? In: R. Bartholo, D. G. Sansolo, \& I. Bursztyn (Eds.). Turismo de base comunitária: diversidade de olhares e experiências brasileiras (pp. 108-121). Rio de Janeiro: Letra e Imagem.

Irving, M. D. A., \& Azevedo, J. (2002). Turismo: o desafio da sustentabilidade. São Paulo: Futura.

Kibicho, W. (2008). Community-based tourism: A factor-cluster segmentation approach. Journal of Sustainable Tourism, 16(2), 211-231. https://doi.org/10.2167/jost623.0

Kim, S., Park, E., \& Phandanouvong, T. (2014). Barriers to Local Residents' Participation in Community-Based Tourism: Lessons from Houay Kaeng Village in Laos. SHS Web of Conferences, 12(December), 01045. https://doi.org/10.1051/shsconf/20141201045

Koseoglu, M. A., Rahimi, R., Okumus, F., \& Liu, J. (2016). Bibliometric studies in tourism. Annals of Tourism Research, 61, 180-198. https://doi.org/10.1016/j.annals.2016.10.006

Lobato, A. S. (2013). Turismo de base comunitária e desenvolvimento socioespacial : um diálogo possível. Revista Brasileira de Ecoturismo, 6(3), 648-661. https://doi.org/10.34024/rbecotur.2019.v12.9449

López-Guzmán, T., Sánchez-Cañizares, S., \& Pavón, V. (2011). Community - Based Tourism in Developing Countries : a Case Study. Tourism: An International Multidisciplinary Journal of Tourism, 6(1), 69-84. Retrieved from http://www.chios.aegean.gr/tourism/VOLUME_6_No1_art04.pdf?origin=publicati

Maldonado, C. (2009). O turismo rural comunitário na América Latina: gênesis, características e políticas. In: R. Bartholo, D. G. Sansolo, \& I. Bursztyn (Eds.) Turismo de base comunitária: diversidade de olhares e experiências brasileiras (pp. 25-44). Rio de Janeiro: Letra e Imagem.

Mayaka, M., Croy, W. G., \& Cox, J. W. (2018). Participation as motif in community-based tourism: a practice perspective. Journal of Sustainable Tourism, 26(3), 416-432. https://doi.org/10.1080/09669582.2017.1359278

Mello, I. R., Dantas, K. M. F. B. J. A., \& Botelho, D. R. (2017). 25 anos de publicação em auditoria : análise bibliométrica sob o ponto de vista da Lei de Lotka , Lei de Zipf e Ponto de Transição ( T ) de Goffman. Revista de Estudos Contábeis, 8(15), 45-65. Retrieved from http://www.uel.br/revistas/uel/index.php/rec/article/view/32197/23464

Mielke, E. J. C. (2009). Desenvolvimento Turístico de Base Comunitária. Campinas: Alínea.

Mielke, E. J. C., \& Pegas, F. V. (2013). Turismo de Base Comunitária no Brasil. Insustentabilidade é uma Questão de Gestão. Turismo Em Análise, 24(1), 170-189. https://doi.org/10.11606/issn.19844867.v24i1p170-189

MTUR, M. do T. (2010). Dinâmica e diversidade do turismo de base comunitária: desafio para a formulação de política pública. Retrieved from http://www.turismo.gov.br/export/sites/default/turismo/o_ministerio/publicacoes/downloads_publicacoes/

Nair, V., Mohamad, N. H., \& Hamzah, A. (2013). Tourism cooperative for scaling up community $\square$ based tourism. Worldwide Hospitality and Tourism Themes, 5(4), 315-328. https://doi.org/10.1108/WHATT-032013-0017

Nechar, M. C., \& Panosso Netto, A. (2010). Implicaciones epistemológicas en la construcción del conocimiento del turismo. In: M. C. Nechar \& A. Panosso Netto (Eds.) Epistemología del turismo: estudios críticos (1st ed., pp. 15-40). México: Editorial Trilhas.

Nyaupane, G. P., Morais, D. B., \& Dowler, L. (2006). The role of community involvement and number/type of visitors on tourism impacts: a controlled comparison of annapurna, Nepal and Northwest Yunnan, China. Tourism Management, 27(6), 1373-1385. https://doi.org/10.1016/j.tourman.2005.12.013 
Okazaki, E. (2008). A community-based tourism model: Its conception and use. Journal of Sustainable Tourism, 16(5), 511-529. https://doi.org/10.1080/09669580802159594

Palacios, C. G. (2016). Turismo comunitario en ecuador: ?quo vadis? Estudios y Perspectivas En Turismo, 25(Especial), 597-614. Retrieved from https://dialnet.unirioja.es/servlet/articulo?codigo=6333383

Quevedo-Silva, F., Santos, E. B., Brandão, M. M., \& Vils, L. (2016). Estudo bibliométrico: orientações sobre sua aplicação. Revista Brasileira de Marketing, 15(02), 246-262. https://doi.org/10.5585/remark.v15i2.3274

Ruiz-Ballesteros, E., \& Cáceres-Feria, R. (2016). Community-building and amenity migration in communitybased tourism development. An approach from southwest Spain. Tourism Management, 54, 513-523. https://doi.org/10.1016/j.tourman.2016.01.008

Sampaio, C. A. C. (2013). Turismo como Fenômeno Humano : prlnclplos para pensar a ecossocioeconomia do turismo e sua prática sob a denominação turismo comunitário. Turismo Em Análise, 18(2), 148-165. https://doi.org/10.11606/issn.1984-4867.v18i2p148-165

Sampaio, C. A. C., \& Coriolano, L. N. (2009). Dialogando com experiências vivenciadas em Marraquech e America Latina para compreensão do Turismo Comunitário e Solidário. Revista Brasileira de Pesquisa Em Turismo, 3(1), 4-24. https://doi.org/10.7784/rbtur.v3i1.125

Sampaio, C. A. C., \& Zamignan, G. (2012). Estudo da demanda turística: experiência de turismo comunitário da microbacia do rio Sagrado, Morretes (PR). Cultur - Revista de Cultura e Turismo, 6(1), 25-39. Retrieved from http://each.usp.br/turismo/publicacoesdeturismo/ref.php?id=25524

Sampaio, C. A. C., Zechner, T., Henríquez, C., Coriolano, L. N. M. T., \& Fernandes, S. (2014). Turismo comunitário a partir de experiências brasileiras, chilenas e costarriquenha. Revista Brasileira de Pesquisa Em Turismo, 8(1), 42-58. https://doi.org/https://doi.org/10.7784/rbtur.v8i1.575

Sancho, A., \& Malta, G. (2015). Pesquisa de Demanda para Turismo de Base Comunitária : desafios à promoção do encontro entre comunidades e viajantes. Turismo Em Análise, 26(1), 38-67. https://doi.org/10.11606/issn.1984-4867.v26i1p38-67

Sansolo, D. G., \& Bursztyn, I. (2009). Turismo de base comunitária: potencialidade no espaço rural brasileiro. In: R. Bartholo, D. G. Sansolo, \& I. Bursztyn (Eds.), Turismo de base comunitária: diversidade de olhares e experiências brasileiras (pp. 142-161). Rio de Janeiro: Letra e Imagem.

Sen, A. (2010). Desenvolvimento com liberdade. São Paulo: Comapnhai de Bolso.

Silva, F. de P. S. da, Malta, A. E. R., \& Sá, N. S. C. de. (2016). Turismo de base comunitária no antigo Quilombo Cabula. Caderno de Estudos e Pesquisas Do Turismo, 16(2), $79-92$. https://doi.org/10.18472/cvt.16n2.2016.1149

Silva, F. de P. S., \& Martins, L. C. de A. (2012). Mergulhando em memórias , tecendo culturas e construindo histórias : o diálogo entre a história e o turismo de base comunitária. Sustentabilidade Em Debate, 3(2), 6170.

Sin, H. L., \& Minca, C. (2014). Touring responsibility: The trouble with "going local" in community-based tourism in Thailand. Geoforum, 51, 96-106. https://doi.org/10.1016/j.geoforum.2013.10.004

Sudhier, K. G. (2014). Application of bradford's law of scattering to the physics literature: a study of doctoral theses citations at the indian institute of science. DESIDOC Journal of Library \& Information Technology, 30(2), 3-14. https://doi.org/10.14429/djlit.30.3

Tasci, A. D. A., Croes, R., \& Villanueva, J. B. (2014). Rise and fall of community-based tourism - facilitators, inhibitors and outcomes. Worldwide Hospitality and Tourism Themes, 6(3), 261-276. https://doi.org/10.1108/WHATT-03-2014-0012

Thompson, D. F., \& Walker, C. K. (2015). A descriptive and historical review of bibliometrics with applications to medical sciences. Pharmacotherapy, 35(6), 551-559. https://doi.org/10.1002/phar.1586

Timothy, D. J. (2007). Empowerment and stakeholder participation in tourism destination communities. In: A. Church \& T. Coles (Eds.), Tourism, Power and Space (pp. 199-216). London: Routledge.

Tolkach, D., \& King, B. (2015). Strengthening Community-Based Tourism in a new resource-based island nation: Why and how? Tourism Management, 48, 386-398. https://doi.org/10.1016/j.tour$\underline{\text { man.2014.12.013 }}$ 
Torraco, R. J. (2016). Writing Integrative Literature Reviews. Human Resource Development Review, 15(4), 404-428. https://doi.org/10.1177/1534484316671606

Urbizagastegui, R. (2008). A produtividade dos autores sobre a Lei de Lotka. Ciência Da Informação, 37(2), 87-102. https://doi.org/10.1590/S0100-19652008000200007

Villavicencio, B. P., Zamora, J. G., \& Pardo, G. L. (2016). El Turismo Comunitario en la Sierra Norte de Oaxaca: Perspectiva desde las instituciones y la gobernanza en territorios indígenas. El Periplo Sustentable, 30(Enero/Junio), 6-37. Retrieved from http://ru.iiec.unam.mx/id/eprint/3137

Zaoual, H. (2009). Do turismo de massa ao turismo situado. In: R. Bartholo, D. G. Sansolo, \& I. Bursztyn (Eds.), Turismo de base comunitária: diversidade de olhares e experiências brasileiras (pp. 55-72). Rio de Janeiro: Letra e Imagem.

Vigolo, V. \& Confente, I. (2014). Older Tourists: An Exploratory Study on Online Behaviour. Proceedings of the International Conference in Dublin, Information and Communication Technologies in Tourism, Irlanda.

Visão geral da viagem online da América Latina Terceira edição (2016). Recuperado em 11 Maio, 2017, de http://www.phocuswright.com/Travel-Research/Market-Overview-Sizing/Latin-America-Online-Travel-Overview-Third-Edition.

\section{Informações dos autores}

\section{Pollyanna Fraga Graciano}

Mestre em Hotelaria e Turismo pela Universidade Federal de Pernambuco. Tem graduação em Turismo pela Universidade Federal de Pernambuco.

Suas contribuições no artigo estão nas seguintes atividades: definição do tema, desenvolvimento do esboço inicial da proposta da pesquisa, realização da coleta de dados, análise dos dados e elaboração da conclusão do estudo.

E-mail: lyafraga@gmail.com

ORCID: https://orcid.org/0000-0002-6736-7961

\section{Luciana Araújo de Holanda}

Doutora e Mestre em Administração pela Universidade Federal de Pernambuco. Tem graduação em Turismo pela Universidade Católica de Pernambuco. Atualmente, integra o quadro da Universidade Federal de Pernambuco como Professora Adjunta IV.

Suas contribuições para o trabalho incluem, mas não se limitam a, escolha do tema, criação da equipe de pesquisa, definição da metodologia empregada e revisão de versões preliminares do artigo.

Email: Iuciana.holanda@ufpe.br

ORCID: https://orcid.org/0000-0001-7312-5267 